\title{
About Unsteady Magnetopolar free Convection flow cdots in a Slip flow Regime
}

\author{
Uthman ibn Afaq
}

\begin{abstract}
It is written that The objective of this paper is to study the effects of different parameters on an unsteady magnetopolar free convection flow of an incompressible fluid in the presence of thermal radiation and uniform magnetic field of strength BO through a porous medium in slip flow regime. The suction velocity is considered to be variable and the fluid is assumed to be gray; emitting absorbing but non scattering medium. The governing boundary layer equations with the boundary conditions are first converted into dimensionless form by non-similar transformations, and then resulting system of coupled non-linear partial differential equations are solved by series expansion method. The expressions for velocity (u), angular velocity ( $\omega)$, temperature $(\theta)$, concentration $(C)$, skin friction $(C f)$ and rate of heat transfer $(N u)$ are obtained. The results obtained have been presented, separately in two basic fluids air $(\operatorname{Pr}=0.71, S c=0.22)$ and water $(\operatorname{Pr}=7, S c=0.61)$, numerically through graphs to observe the effects of different parameters and the physical aspect of the problem. We observe that on decreasing Gr (thermal Grashof number), skin friction drops in air but rises in water. Also we notice that the rate of heat transfer rises on decreasing h2 (jump parameter).
\end{abstract}

\section{REFERENCES}

[1]. Schunk, D. H., \& DiBenedetto, M. K. (2020). Motivation and social cognitive theory. Contemporary Educational Psychology, 60, 101832 .

[2]. Dorfman, B. S., \& Fortus, D. (2019). Students' self-efficacy for science in different school systems. Journal of Research in Science Teaching, 56(8), 1037-1059.

[3]. Brew, E. (2019). Determinants of low performance of female students In science subject: a survey of junior high schools in the Aowin district (Doctoral dissertation, University of Cape coast).

[4]. Falco, L. D., \& Summers, J. J. (2019). Social Persuasions in Math and Their Prediction of STEM Courses Self-Efficacy in Middle School. The Journal of Experimental Education, 1-18.

[5]. Ntarmah, A. H., Gyan, M. K., Gyedu, S., \& Cobbinah, E. The Predictive Power of Sources of Teacher Efficacy beliefs on Economics Teachers' Efficacy beliefs in the Implementation of Senior High School Economics Curriculum.

[6]. McBride, E., Oswald, W. W., Beck, L. A., \& Vashlishan Murray, A. (2019). "I'm just not that great at science": Science self-efficacy in arts and communication students. Journal of Research in Science Teaching.

[7]. Deel, C. M. (2019). Causal-Comparative Study of Reading Self-Efficacy of Senior High School Students Based on English Course Placement.

[8]. Probst, J. R. (2019). A Causal-Comparative Analysis of Mathematics Self-Efficacy Based on Gender and Math Acceleration.

[9]. La Ode Ahmad Jazuli, E. S., \& Syahrial, Z. The Effect of Brain Based Learning Strategies and Project Based Learning on Mathematics Learning Outcomes in Students of the Kinesthetic Learning Style Group.

[10]. Pei-Boon, O., Wan Jaafar, W. M., Chin-Siang, A., \& Nee-Nee, C. (2020). Psychometric Properties of the Sources of Counseling Self Efficacy in a Sample of Malaysian Secondary School Counselors. SAGE Open, 10(1), 2158244020902076.

[11]. ibn Afaq, U. A Comparative Study of the Qu'ranic Correctness Claims between Wahid and Tahara.

[12]. Hiroki, T. 統計から見る大卒と高卒の賃金格差について.

[13]. Hiroki, T. (2019). The Mathematical Expressions of Quranic Exegeses and the Mathematical Definition of the Quranic Correctness.

[14]. Hiroki, T. (2019). Methodology to Prove the Quranic Correctness. 